\title{
SELEÇÃO E CARACTERIZAÇÃO MOLECULAR DE BACILLUS THURINGIENSIS BERLINER COM ATIVIDADE TÓXICA PARA TRICHOPLUSIA NI HUEBNER (LEPIDOPTERA: NOCTUIDAE)
}

\author{
E.D. Grecco ${ }^{1}$, R.A. Polanczyk ${ }^{2}$, D. Pratissoli ${ }^{1}$ \\ ${ }^{1}$ Universidade Federal do Espírito Santo, Centro de Ciências Agrárias, Departamento de Produção Vegetal, \\ Laboratório de Entomologia, C.P16, CEP29500-000, Alegre, ES, Brasil.E-mail: grecco.eduardo@yahoo.com.br
}

\section{RESUMO}

Trichoplusia ni é uma praga polífaga importante em plantios de crucíferas, soja e algodão. O presente estudo objetivou selecionar e caracterizar por método molecular isolados de Bacillus thuringiensis $(\mathrm{Bt})$ com potencial para atuar com agentes de controle biológico de T. ni. Para os bioensaios de patogenicidade, uma alíquota com $3 \times 10^{8}$ esporos $/ \mathrm{mL}$ de suspensão de Bt de cada isolado foi aplicada na superfície do disco de dieta artificial, previamente distribuída em placas de acrílico com 50 lagartas, distribuídas em 5 repetições. Nos bioensaios para a obtenção da $\mathrm{CL}_{50^{\prime}}$ apenas os isolados com $100 \%$ de mortalidade foram pré-selecionados, sendo testadas as seguintes concentrações: $10^{2}, 5 \times 10^{2}, 10^{3}, 2 \times 10^{3}, 4 \times 10^{3}, 6 \times 10^{3}, 8 \times 10^{3}$ esporos $/ \mathrm{mL}$, sendo os tratamentos compostos por 120 lagartas, distribuídas em 3 repetições. Foi feita caracterização molecular para detectar os genes cry1, cry2 e Vip para os isolados que obtiveram mortalidade acima de $95 \%$. Os isolados HD-1 (Padrão), Bt-1043N-V, Bt-1034F, Bt-1009K, Bt-1000, Bt-969A causaram 100\% de mortalidade nos testes de patogenicidade e $\mathrm{CL}_{50}$ de $1,17 \times 10^{3}, 1,45 \times 10^{3}, 1,46 \times 10^{3}, 1,01 \times 10^{3}$, $9,43 \times 10^{2}, 1,22 \times 10^{3}$, respectivamente. Não foram encontrados genes cry1, cry 2 e Vip nos isolados testados, podendo outras toxinas Cry estar causando a mortalidade de T. ni, visto que os isolados testados são específicos para a ordem Lepidoptera. Estes isolados mostraram potencial para o controle de T. ni, sendo virulentos a este inseto, com potencial para serem utilizados em programa de manejo desta praga.

PALAVRAS-CHAVE: MIP, controle biológico, entomopatógeno, toxinas Cry.

\begin{abstract}
SELECTION AND MOLECULAR CHARACTERIZATION OF BACILLUS THURINGIENSIS BERLINER WITH TOXIC ACTIVITY AGAINST TRICHOPLUSIA NI HUEBNER (LEPIDOPTERA: NOCTUIDAE). Trichoplusia $n i$ is a polyphagous pest that is becoming a major pest in plantations of cruciferous crops, soybeans and cotton. This study was aimed to select and molecularly characterize efficient isolates of Bacillus thuringiensis (Bt) for the control of T. ni. For the bioassays of pathogenicity, an aliquot with a $3 \times 108$ spores/mL suspension of Bt of each isolate was applied on the surface of the artificial diet disk, previously distributed on acrylic plates with 50 larvae, distributed in 5 repetitions. In bioassays to obtain the $\mathrm{LC}_{50^{\prime}}$ only isolates with $100 \%$ mortality were preselected, and tests were carried out at the concentrations $10^{2}, 5 \times 10^{2}, 10^{3}, 2 \times 10^{3}, 4 \times 10^{3}, 6 \times 10^{3}$, and $8 \times 10^{3}$ spores $/ \mathrm{mL}$, and the treatments consisting of 120 larvae, distributed in 3 repetitions. A molecular characterization was performed to detect the genes cry1, cry2 and Vip for the isolates which obtained mortality over 95\%. Isolates HD-1 (Standard), Bt-1043N-V, Bt-1034F, Bt-1009K, Bt-1000 and Bt-969A caused 100\% mortality in the test for pathogenicity and presented an LC $_{50}$ of $1.17 \times 10^{3}, 1.45 \times 10^{3}, 1,46 \times 10^{3}, 1.01 \times 10^{3}, 9.43 \times 10^{2}, 1.22 \times 10^{3}$, respectively. Genes cry 1, cry 2 and Vip were not found in the isolates tested, and other Cry toxins may have been causing the mortality of $T$. $n i$, since the isolates tested are specific for the Lepidoptera order. These isolates showed potential for the control of T. ni, being aggressive to this insect, with a potential to be used in a pest management program for this species.
\end{abstract}

KEY WORDS: IPM, biological control, entomopathogen, Cry toxins.

${ }^{2}$ Universidade Estadual Paulista, Departamento de Fitossanidade, Jaboticabal, SP, Brasil. 


\section{INTRODUÇÃO}

Trichoplusia ni (Lepidoptera: Noctuidae) é uma espécie polífaga com cerca de 160 espécies de plantas hospedeiras. Dentre essas, podemos destacar as crucíferas, além de soja e algodão, pela importância econômica. As lagartas se alimentam das plantas, reduzindo a área foliar, prejudicando a fotossíntese (Shorey et al., 1962; SHelton et al., 1982; Jost; Pitre, 2002).

Tradicionalmente, o controle dessa praga é realizado com aplicações de inseticidas de amplo espectro, incluin-do os carbamatos, organofosforados e piretroides. No entanto, a popularização do uso de agroquímicos como forma única de controle de pragas culminou no seu uso indiscriminado causando muitos problemas, como a resistência de insetos e ácaros, os ataques intensos de pragas tidas como secundárias, a ressurgência de pragas, os desequilíbrios biológicos e efeitos prejudiciais ao homem, os insetos úteis e outros organismos, além de resíduos nos alimentos, água e solo (GALLO et al., 2002; PARRA et al., 2002).

Entre os organismos promissores que podem ser utilizados no controle biológico de pragas agrícolas, destacam-se os entomopatógenosque representaram cerca de $41 \%$ do volume dos produtos biológicos comercializados no mercado mundial com um faturamento previsto para 330 milhões de dólares em 2008 (GuILON, 2008).

Atualmente, são conhecidos muitos microorganismos entomopatogênicos, especialmente fungos, vírus e bactérias, que podem ser empregados no controle biológico (VALADARES-INGLIs et al., 1998). Além disso, a utilização de inseticidas biológicos no controle de pragas apresenta diversas vantagens para o agroecossistema, em comparação com o uso dos inseticidas químicos, como a preservação dos inimigos naturais, menos agressão ao meio ambiente e produto final com mais qualidade(MosCARDI, 1999).

Dentre os micro-organismos empregados no controle biológico, a bactéria Bacillus thuringiensis (Bt) (Bacillaceae) destaca-se por apresentar atividade tóxica a diversas espécies de pragas agrícolas e urbanas, sendo formadora de esporos capaz de produzir inclusões cristalinas durante a esporulação (Glare; O' Callagham, 2000; PolanczyK; Alves, 2003). $\mathrm{O}$ número de isolados de $\mathrm{Bt}$ que exibem alta atividade inseticida vem crescendo, porém, os produtos comerciais de bioinseticidas atualmente usados no controle de pragas de lepidópteros são constituídos por poucos isolados, podendo aumentar rapidamente a frequência deindivíduos resistentes dentro de uma população a esses bioinseticidas (SwIECiCKA et al., 2008), pois já se detectou resistência em populações de estufas e campo de T. ni a produtos de Bt kurstaki (Btk) (JANMAAT; MYers, 2003).
A variabilidade genética existente entre diferentes isolados de Bt é caracterizada principalmente por meio da utilização de técnicas que têm como base a reação em cadeia da DNA polimerase (PCR), muitas vezes evidenciando a presença de genes desconhecidos e detectando diferenças entre as estirpes de Bt (CERón et al., 1995; Bravo et al., 1998; Lima et al., 2002). Um aspecto importante no desenvolvimento de um novo bioinseticidas é a descoberta de estirpes com maior atividade e melhor adaptadas às condições ambientais onde esses produtos serão utilizados (DiAs, 1992).

Este trabalho teve como objetivo selecionar e carac-terizar por método molecular os isolados de Bt com potencial de ação tóxica para T. ni.

\section{MATERIAL E MÉTODOS}

Os 60 isolados de Bt utilizados nos experimentos foram cedidos pelo Laboratório de Genética de Bactérias e Biotecnologia Aplicada (LGBBA), junto ao Departamento de Biologia Aplicada a Agropecuária da Faculdade de Ciências Agrárias e Veterinárias, Campus de Jaboticabal,SP. Os isolados dessa coleção foram estocados na forma de fitas de papel filtro impregnados com uma suspensão de esporos, e mantidos a $4^{\circ} \mathrm{C}$ no Núcleo de Desenvolvimento de Manejo Fitossanitário de Pragas e Doenças (NUDEMAFI) do Centro de Ciências Agrárias da Universidade Federal do Espírito Santo (CCA-UFES), em Alegre, ES.

Os isolados de $\mathrm{Bt}$ utilizados neste trabalho foram coletados em solos de diferentes locais do Brasil. Utilizou-se o isolado HD-1 (Btk) como padrão.

Coleta e criação de T.ni. A criação foi iniciada a partir de coletas manuais de lagartas de T. ni no Distrito de Aracê no Município de Domingos Martins, Espírito Santo, Brasil, em cultivos de repolho e couve-flor, sendo acondicionadas em caixa de isolamento térmico. No Laboratório do NUDEMAFI foram alimentadas com folhas de couve até as lagartas atingirem o estágio de pupa. Em seguida, foram transferidas para um recipiente $(150 \times 150$ $\mathrm{mm}$ ) com papel filtro umedecido e acondicionado em gaiolas de madeira $(700 \times 600 \times 500 \mathrm{~mm})$ revestidas por te-flon. Após a emergência, os adultos foram colocados em gaiolas com folhas de couve para oviposição. Os adultos foram alimentados com solução de mel a 10\% em chumaço de algodão. Os ovos foram coletados a cada $24 \mathrm{~h}$, sendo que $10 \%$ destes foram utilizados para a manutenção da criação e o restante para a realização dos bioensaios. A dieta artificial utilizada para manutenção da praga foi desenvolvida por BURTON (1969) e duas lagartas de T. ni recém- eclodidas ( \pm 3 dias) foram 
inoculadas em cada tubo de ensaio $(80 \mathrm{~mm} \times 25$ $\mathrm{mm})$. A criação permaneceu em sala climatizada a $25 \pm 2,0^{\circ} \mathrm{C}, 60 \pm 15 \%$ de U.R e $14 \mathrm{~h}$ de fotofase. A cada seis meses foram efetuadas a reintrodução de novos espécimes, com o objetivo de diminuir a degeneração da criação.

Condução dos experimentos. Os isolados foram multiplicados em meio de cultura BHI ("brain heart infusion" ou infusão de cérebro e coração - Biobrás) a $30^{\circ} \mathrm{C}$, sob agitação orbital a $180 \mathrm{rpm}$ por $72 \mathrm{~h}$ para um crescimento padrão deles. Após a lise bacteriana, a mistura contendo esporos, cristais e células vegetativas foram submetidas a 3 centrifugações consecutivas de $5.000 \mathrm{rpm}$ por $20 \mathrm{~min}$, a fim de eliminar o meio de cultura. Em seguida, uma alíquota de $1 \mathrm{~mL}$ de uma suspensão contendo $10 \mathrm{~mL}$ foi diluída 1.000 vezes em água destilada e esteri-lizada, e a concentração de esporos determinada por meio de leitura em câmara de Neubauer conforme método descrito em Alves; Moraes (1998).

Para a execução dos bioensaios de patogenicidade foram utilizadas lagartas de primeiro ínstar de T. ni, sendo conduzidos em câmara de fluxo laminar, previamente esterilizada com luz ultravioleta por $20 \mathrm{~min}$. A suspensão de Bt contendo $3 \times 10^{8}$ esporos $/ \mathrm{mL}$ foi aplicada na superfície do disco de dieta artificial desenvolvida por BURTON (1969). Após a absorção e evaporação do excesso de água, 50 lagartas de primeiro ínstar de T. ni, distribuídas em 5 repetições, foram acondicionadas individualmente em gerbox plástico $(65 \times 25 \mathrm{~mm})$. Para o controle foi aplicado água destilada e esterilizada em autoclave vertical por $20 \mathrm{~min}$ a $1 \mathrm{kgf}$.

Os bioensaios permaneceram em câmara climatizada a $25 \pm 1,0^{\circ} \mathrm{C}, 65 \pm 10 \%$ de U.Re 14 h de fotofase, sendo avaliados após 5 dias. O critério de mortalidade usado para as lagartas foi o de estar imóvel e escurecida ou que nãoconseguisse se locomover uma distância igual a do seu corpo. Os dados observados foram corrigidos pela fórmula* de Аввотт (1925) е submetidos à análise de variância e posteriormente ao teste de Scott-Knott, ao nível de 5\%, ou seja:

Os isolados de Bt que causaram $100 \%$ de mortalidade nos testes de patogenicidade foram submetidos aos bioensaios para a estimativa da $\mathrm{CL}_{50}$ onde foram utilizados os mesmos substratos alimentarese condições de ambiente mencionadas nos bioensaios de patogenicidade.

A amplitude das concentrações testadas foi préestabelecida em ensaio preliminar em valores que atendessem às exigências da análise de Probit $(5 \mathrm{a}$
95\%) de mortalidade. Para cada isolado foram testadas sete concentrações espaçadas logaritmicamente e controle (água destilada e autoclavada), com 120 lagartas, distribuídas em 3 repetições para cada concentração, totalizando 960 insetos por isolado. Os bioensaios de estimativa da $\mathrm{CL}_{50}$ foram avaliados a cada 24 h, até o quinto dia após a aplicação. Os dados de mortalidade foram corrigidos e submetidos a análise de Probit com a utilização do programa POLO-PC (Análise deProbit), (LeORA SOFtwARE, 1987).

Caracterização molecular dos isolados de Bt. Para a realização das análises de Reação da Polimerase em Cadeia (PCR), o material genético de cada um dos isolados foi obtido com a utilização de resina de troca iônica InstaGene Matrix, produzida pela Bio-Rad $\AA$, seguindo as instruções do fabricante como descritas abaixo:

Os isolados de Bt foram obtidos pela inoculação de uma alíquota da solução estoque de esporos, em placas de Petri, contendo meio BHI ("brain heart infusion" ou infusão de cérebro e coração - Biobrás), incubadas em B.O.D. (Biological Oxygen Demand), a $30 \pm 0,5^{\circ} \mathrm{C}$ por $18 \mathrm{~h}$ e suspensas novamente em tubos para microcentrífuga de $1,5 \mathrm{~mL}$ contendo $1,0 \mathrm{~mL}$ de água destilada esterilizada e centrifugadas a 15.000 rpm por 2 min a $20^{\circ} \mathrm{C}$.

Após centrifugação, o sobrenadante foi descartado, sendo adicionados $200 \mathrm{~mL}$ da Matriz InstaGene Matrix (Bio-Rad®) e, em seguida, o material foi incubado em banho aquecido a $56^{\circ} \mathrm{C}$ por $20 \mathrm{~min}$, agitado rigorosamente em aparelho do tipo 'Vortex' por 10 segundos e incubado em água fervente $\left(100^{\circ}\right.$ C) por $8 \mathrm{~min}$. A amostra foi novamente agitada em aparelho do tipo 'Vortex' por 10s e centrifugada a $20^{\circ} \mathrm{C}$ por $3 \mathrm{~min}$. Por fim, $200 \mathrm{~mL}$ do sobrenadante foram colhidos e transferidos para outro tubo de microcentrifuga esterilizado e o DNA armazenado a $-20^{\circ} \mathrm{C}$ até ser utilizado.

Além das extrações dos DNA genômicos dos isolados utilizados, foi também extraído DNA das linhagens padrão: Bt subsp. kurstaki - HD-1 (Lepidoptera-específico), Bt subsp. tenebrionis (Coleoptera - específico), que foram utilizadas como controles positivos e negativos nas reações de amplificação por PCR. Os iniciadores para os genes cry1, cry2 e Vip foram elaborados e otimizados no laboratório de Genética de Bactérias e Biotecnologia Aplicada.

As reações de amplificação foram realizadas em aparelho termociclador (PTC - 100 "Programmable Thermal Controller" - MJ Research, inc.), equipado com circuito "Hot Bonnet".

*Mortalidade corrigida $=\%$ de mortalidade no tratamento $\%$ de mortalidade na testemunha $\times 100$ 100 - \% de mortalidade na testemunha 
Após as amplificações, $5 \mathrm{~mL}$ das amostras foram transferidos para outro tubo plástico e foi adicionado às amostras $3 \mathrm{~mL}$ de tampão de amostra ("loading buffer" - 0,5\% de azul de bromofenol em glicerol 50\%). O volume total de $8 \mathrm{~mL}$ de cada amostra foi aplicado em gel de agarose a $1,5 \%$, contendo brometo de etídeo $(0,5$ $\mathrm{mg} / \mathrm{mL}$ ) e submetido à eletroforese horizontal em cuba tipo "sunrise" (96 canaletas), por $2 \mathrm{~h}$, a $70 \mathrm{~V}$, conduzida em tampão TEB 1X (Tris $89 \mathrm{mM}$, EDTA 2,5 mM e Acido Bórico $89 \mathrm{mM}$ com $\mathrm{pH}$ $8,3)$, também adicionado de brometo de etídeo $(0,5 \mathrm{mg} / \mathrm{mL})$. Em todas as eletroforeses realizadas foi adotado o emprego de uma amostra de DNA, com fragmentos de tamanhos conhecidos, múltiplos de $1 \mathrm{~Kb}$ de DNA ladder ${ }^{\circledR}$ ", produzida pela Invitrogen, a qual serviu como referência de migração eletroforética para verificação dos tamanhos dos fragmentos obtidos nas reações de amplificação. Utilizou-se, também, o controle negativo da reação no qual foi colocada água estéril em substituição ao DNA genômico.
Os géis de agarose foram visualizados sob luz ultravioleta e fotodocumentados em equipamento fotodocumentador (GEL DOC 2000 - Bio-Rad®), através do software Quantity-one.

\section{RESULTADOS E DISCUSSÃO}

Os resultados encontrados evidenciam que há efeito de Bt sobre T. ni ( $\mathrm{F}=10,126 ; \mathrm{P} \geq 0,000001$; g.1 $=244)($ Tabela 1). Entre os isolados testados, $27(45 \%)$ apresentam mortalidade corrigida acima de $80 \%$ e dentre estes $5(8,33 \%)$ apresentam uma mortalidade de $100 \%$, a mesma obtida pelo Btk nos testes de patogenicidade. Dos outros, em 14 isolados $(23,33 \%)$ constatou-se uma mortalidade entre 59 e $79 \%$, em 9 isolados ( $15 \%$ ) entre 38 e $54 \%$ e 10 isolados $(16,66 \%)$ entre 22,5 e $34 \%$ (Tabela 1 ). Estes resultados mostram que 27 isolados são promissores para o controle de T. ni e podem ser usados em futuros trabalhos para o controle dessa praga.

Tabela 1 - Mortalidade corrigida (\%) ( $\pm \mathrm{EP})$ de Trichoplusia ni (Lepidoptera: Noctuidae) inoculadas em dieta artificial contendo suspensão de diferentes isolados de Bacillus thuringiensis, a $25 \pm 1,0^{\circ}$ C, U.R $65 \pm 10 \%$ e fotofase $14 \mathrm{~h}$.

\begin{tabular}{|c|c|c|c|}
\hline Isolados & Mortalidade (\%) & Isolados & Mortalidade (\%) \\
\hline Bt - HD-1 (Padrão) & $100,00 \pm 0,00 \mathrm{~A}$ & Bt - 1048NM & $\mathrm{Bt}-1048 \mathrm{NM}$ \\
\hline $\mathrm{Bt}-1034 \mathrm{~F}$ & $100,00 \pm 0,00 \mathrm{~A}$ & Bt - 1012 & $82,97 \pm 10,41 \mathrm{~A}$ \\
\hline $\mathrm{Bt}-1009 \mathrm{~K}$ & $100,00 \pm 0,00 \mathrm{~A}$ & $\mathrm{Bt}-775 \mathrm{G}$ & $82,97 \pm 12,44 \mathrm{~A}$ \\
\hline Bt -1000 & $100,00 \pm 0,00 \mathrm{~A}$ & $\mathrm{Bt}-\mathrm{S} 165$ & $80,85 \pm 12,13 \mathrm{~A}$ \\
\hline $\mathrm{Bt}-969 \mathrm{~A}$ & $100,00 \pm 0,00 \mathrm{~A}$ & $\mathrm{Bt}-\mathrm{S} 1328$ & $80,85 \pm 11,32 \mathrm{~A}$ \\
\hline Bt $-1043 \mathrm{~N}-\mathrm{V}$ & $100,00 \pm 0,00 \mathrm{~A}$ & Bt - $1043 \mathrm{~N}-\mathrm{V}$ & $80,85 \pm 8,51 \mathrm{~A}$ \\
\hline Bt - 1044CN-V & $97,87 \pm 2,12 \mathrm{~A}$ & Bt - 1010I & $80,85 \pm 12,02 \mathrm{~A}$ \\
\hline $\mathrm{Bt}-1038 \mathrm{~K}$ & $97,87 \pm 12,25 \mathrm{~A}$ & Bt - S244 & $78,72 \pm 12,10 \mathrm{~B}$ \\
\hline $\mathrm{Bt}-1001$ & $97,87 \pm 2,12 \mathrm{~A}$ & $\mathrm{Bt}-867 \mathrm{BC}$ & $72,34 \pm 10,00 \mathrm{~B}$ \\
\hline $\mathrm{Bt}-1077 \mathrm{C}$ & $95,74 \pm 12,17 \mathrm{~A}$ & $\mathrm{Bt}-810 \mathrm{~B}$ & $72,34 \pm 12,20 \mathrm{~B}$ \\
\hline Bt - 1077C & $93,61 \pm 11,93 \mathrm{~A}$ & $\mathrm{Bt}-766 \mathrm{~B}$ & $72,34 \pm 12,31 \mathrm{~B}$ \\
\hline $\mathrm{Bt}-1030 \mathrm{~A}$ & $93,61 \pm 11,87 \mathrm{~A}$ & Bt -985 & $70,21 \pm 12,30 \mathrm{~B}$ \\
\hline $\mathrm{Bt}-977 \mathrm{FA}$ & $91,61 \pm 12,04 \mathrm{~A}$ & Bt -985 & $70,21 \pm 12,30 \mathrm{~B}$ \\
\hline Bt - 1009SLR & $91,48 \pm 11,62 \mathrm{~A}$ & $\mathrm{Bt}-858 \mathrm{EC}$ & $68,08 \pm 11,46 \mathrm{~B}$ \\
\hline $\mathrm{Bt}-\mathrm{CST} 23.10$ & $91,48 \pm 12,54 \mathrm{~A}$ & $\mathrm{Bt}-775 \mathrm{C}$ & $68,08 \pm 12,20 \mathrm{~B}$ \\
\hline Bt - 1000Q & $91,48 \pm 11,82 \mathrm{~A}$ & $\mathrm{Bt}-775 \mathrm{C}$ & $68,08 \pm 12,20 \mathrm{~B}$ \\
\hline $\mathrm{Bt}-1052 \mathrm{~B}$ & $89,36 \pm 12,36 \mathrm{~A}$ & Bt $-814 B$ & $65,95 \pm 11,75 \mathrm{~B}$ \\
\hline Bt -1005 & $89,36 \pm 11,97 \mathrm{~A}$ & Bt - 928 & $61,70 \pm 8,23 \mathrm{~B}$ \\
\hline $\mathrm{Bt}-1002 \mathrm{~B}$ & $89,36 \pm 11,87 \mathrm{~A}$ & Bt -746 & $61,70 \pm 9,05 \mathrm{~B}$ \\
\hline Bt - 1044CV-N & $87,23 \pm 14,07 \mathrm{~A}$ & $\mathrm{Bt}-886 \mathrm{~F}$ & $61,70 \pm 10,54 \mathrm{~B}$ \\
\hline Bt - 1010J & $87,23 \pm 11,71 \mathrm{~A}$ & $\mathrm{Bt}-858 \mathrm{H}$ & $59,57 \pm 11,27 \mathrm{~B}$ \\
\hline $\mathrm{Bt}-937 \mathrm{H} 2$ & $53,19 \pm 10,59 \mathrm{C}$ & $\mathrm{Bt}-933 \mathrm{E}$ & $26,80 \pm 10,34 \mathrm{D}$ \\
\hline Bt - S646 & $51,06 \pm 12,15 \mathrm{C}$ & $\mathrm{Bt}-888 \mathrm{AD}$ & $26,80 \pm 8,22 \mathrm{D}$ \\
\hline $\mathrm{Bt}-816 \mathrm{~A}$ & $48,93 \pm 12,13 \mathrm{C}$ & $\mathrm{Bt}-878 \mathrm{~B}$ & $25,53 \pm 8,20 \mathrm{D}$ \\
\hline $\mathrm{Bt}-852 \mathrm{~F}$ & $42,55 \pm 12,02 \mathrm{C}$ & Bt - 1133 & $25,53 \pm 8,20 \mathrm{D}$ \\
\hline $\mathrm{Bt}-852 \mathrm{C}$ & $42,55 \pm 12,25 \mathrm{C}$ & Bt - SEIVA 1/1002Y & $24,68 \pm 11,58 \mathrm{D}$ \\
\hline $\mathrm{Bt}-941 \mathrm{D}$ & $40,42 \pm 6,20 \mathrm{C}$ & $\mathrm{Bt}-872 \mathrm{~B}$ & $23,40 \pm 6,05 \mathrm{D}$ \\
\hline $\mathrm{Bt}-979 \mathrm{C}$ & $40,42 \pm 10,39 \mathrm{C}$ & Bt $-862 C$ & $23,40 \pm 5,93 \mathrm{D}$ \\
\hline $\mathrm{Bt}-927 \mathrm{R}$ & $38,29 \pm 10,39 \mathrm{C}$ & $\mathrm{Bt}-868 \mathrm{G}$ & $22,55 \pm 10,67 \mathrm{D}$ \\
\hline $\mathrm{Bt}-862 \mathrm{DE}$ & $38,29 \pm 9,15 \mathrm{C}$ & Bt - 927A9.15 & $22,55 \pm 7,03 \mathrm{D}$ \\
\hline Bt - 1077A & $33,19 \pm 11,45 \mathrm{D}$ & & \\
\hline
\end{tabular}

Médias seguidas pela mesma letra na coluna não diferenciam entre si pelo teste de Scott-Knott a 5\%. 
Tabela 2 - Resultados de dose/resposta de isolados de Bacillus thuringiensis a lagartas de Trichoplusia ni (Lepidoptera: Noctuidae) estudados separadamente.

\begin{tabular}{lccccc}
\hline Isolado & $\mathrm{n}$ & $\mathrm{a}$ & $\begin{array}{c}\mathrm{CL}_{50}\left(\mathrm{IC}_{0,05}\right) \\
\left(10^{2} ; 10^{3}\right)\end{array}$ & $\chi^{2}$ & $\mathrm{~g} .1$ \\
\hline Bt - HD-1(Padrão) & 960 & 1,197 & $1,17 \times 10^{3}(6,04 ; 1,77)$ & $5,59^{\text {ns }}$ & 5 \\
Bt - 1043N-V & 960 & 1,239 & $1,22 \times 10^{3}(8,25 ; 1,64)$ & $3,57^{\text {ns }}$ & 5 \\
Bt - 1034F & 960 & 1,041 & $9,43 \times 10^{2}(5,10 ; 1,44)$ & $5,23^{\text {ns }}$ & 5 \\
Bt - 1009K & 960 & 1,037 & $1,01 \times 10^{3}(5,13 ; 1,58)$ & $6,85^{\text {ns }}$ & 5 \\
Bt - 1000 & 960 & 1,175 & $1,46 \times 10^{3}(7,46 ; 2,21)$ & $5,21^{\text {ns }}$ & 5 \\
Bt - 969A & 960 & 1,218 & $1,45 \times 10^{3}(5,62 ; 2,35)$ & $7,82^{\text {ns }}$ & 5 \\
\hline
\end{tabular}

ns: não significativo; $\mathrm{n}$ = número de insetos/isolado; g.l = graus de liberdade; $\mathrm{a}=$ coeficiente angular.

Para a estimativa da $\mathrm{CL}_{50^{\prime}}$ os dados se ajustaram ao modelo proposto, mostrando um $\chi^{2}$ não significativo e com baixa heterogeneidade. Os intervalos de confiança $(P \geq 0,05)$ mostram que não há diferenças significativas entre os isolados (Tabela 2). O HD-1 (Btk) e o Bt-1043N-V, o Bt-1034F, o Bt-1009K, o Bt1000 e o Bt-969A obtiveram uma $\mathrm{CL}_{50}$ de $1,17 \times 10^{3}$, $1,45 \times 10^{3}, 1,46 \times 10^{3}, 1,01 \times 10^{3}, 0,94 \times 10^{3} \mathrm{e} 1,22 \times 10^{3}$ esporos $/ \mathrm{mL}$, respectivamente. Apesar de não haver diferença estatística, o isolado Bt-1034F apresenta uma $\mathrm{CL}_{50} 19,66 \%$ menor que a $\mathrm{CL}_{50}$ do padrão, evidenciando que pode ser mais eficiente no controle dessa praga emais econômico para ouso de umfuturo formulado, pois necessitará de menos esporos/mL para matar $50 \%$ dos insetos. Porém, novos estudos devem ser feitos para que esses isolados possam ser usados em um futuro bioinseticida.

Para verificar a presença de toxinas cry1, cry2 e Vip nos isolados de $\mathrm{Bt}$, foram testados os isolados: Bt-1043N-V, Bt-1034F, Bt-1009K, Bt-1000, Bt-969A, Bt-1044CN-V, Bt-1044CN-V, Bt-1038K e Bt-1001, que causaram mortalidade acima de $95 \%$. Nenhum fragmento de DNA homólogos aos genes cry1, cry2 e Vip (genes específicos da ordem Lepidoptera) foram encontrados nos isolados testados (Figs. 1, 2 e 3). No entanto, todos os isolados de Bt podem ter novas toxinas Cry para o controle de pragas da ordem Lepidoptera.

Estudos que vêm sendo realizados com Bt no controle de T. ni. MAcIntosh et al. (1990), estudando o efeito de Btk (HD-1: Cry1Ab e HD-73: Cry1Ac) para o controle de $T$. ni, encontraram uma $\mathrm{CL}_{50}$ de 0,19 e 0,09 $\mu \mathrm{g} / \mathrm{mL}$, respectivamente. Porém, SwIECICKA et al. (2008), estudando um isolado de Bt thuringiensis (Cry1Ab) em T. ni, encontraram uma $\mathrm{CL}_{50}$ de $16,9 \mu \mathrm{g} / \mathrm{mL}$ e $29,7 \mu \mathrm{g} / \mathrm{mL}$ em lagartas de segundo e quarto ínstar, respectivamente. Segundo IGNOFFO et al. (1981), o Bt israelensis que é específico para Diptera apresentou uma $\mathrm{CL}_{50}$ de $0,12 \mu \mathrm{g} / \mathrm{mL}$ enquanto o Btk apresentou uma $\mathrm{CL}_{50}$ de $0,016 \mu \mathrm{g} /$ $\mathrm{mL}$. SWIECICKA et al. (2008) encontraram mortalidade de $23,5 \%$ em lagartas de segundo instar de T. ni em suspensão de $1 \times 10^{4}$ esporos e cristais/mL de $\mathrm{Bt}$ após 24h de inoculação. Para lagartas de terceiro instar, foi observada uma mortalidade de $8 \%$ em $24 \mathrm{~h}$ e $40 \%$ em $48 \mathrm{~h}$, em uma suspensão de $2 \times 10^{4}$ esporos e cristais $/ \mathrm{mL}$. Os resultados encontrados neste trabalho mostram uma $\mathrm{CL}_{50}$ entre 0,94 e 1,46 $\times 10^{3}$ esporos/ $\mathrm{mL}$ em lagartas de T. $n i$, valores $10 \mathrm{a}$ 13 vezes menos que os encontrados por SWIECICKA et al. (2008), evidenciando a necessidade de se fazer a $\mathrm{CL}_{50}$ para determinar a agressividade do Bt em T. ni.

Estudos demonstram que o Bt controla diversas pragas agrícolas e urbanas, evidenciando o potencial desse entomopatógeno. PolanczyK (2004), estudando a atividade de diversos isolados de Bt para o controle de Spodoptera frugiperda (Lepidoptera: Noctuidae), uma das pragas mais importantes da agricultura brasileira, principalmente em algodão, alfafa, amendoim, arroz, aveia, batata, batata-doce, cana-de-açúcar, hortaliças, milho, soja e trigo, chegou à mortalidade máxima de $45 \%$. Pratissoli et al. (2007) estudaram o efeito de 31 isolados de Bt em populações de $S$. frugiperda e encontraram 10 isolados para a população do Espírito Santo e 12 para a população de Minas Gerais que causaram 100\% de mortalidade. SiLVA-WERNECK et al. (2000) estudaram o efeito de 205 isolados de Bt sobre $S$. frugiperda e apenas um causou mortalidade de $100 \%$. LOGUERCIO etal. (2001) testaram 3.408 isolados nativos e somente $3,3 \%$ causaram mortalidade acima de $75 \%$, sendo que $52 \%$ do material testado mostrou-se pouco ativo (0 a $10 \%)$.

Um fator importante no manejo da praga e na diminuição de danos causados por ela é quando devemos atuar no seu controle. Lagartas neonatas são mais suscetíveis aos bioinseticidas do que outras que já estão em um estádio superior. Por isso é importante que a aplicação do bioinseticida seja após a eclosão da lagarta, aumentando assim o controle e a diminuição de possível aumento de insetos resistentes na população ao bioinseticida.

Outro fator que deve ser considerado é o efeito subletal que esses isolados causam nos sobreviven- 
tes após as aplicações de bioinseticidas, pois alguns isolados de Bt são capazes de afetar a fisiologia dos insetos adultos, refletindo na quantidade e qualidade da oviposição, tornando-se incapazes de causar dano econômico às plantas. AbDUL-SATTAR; WATSON (1982) verificaram que o Bt afetou os adultos de $H$. virescens prejudicando o acasalamento e a oviposição, sendo que a fecundidade dos ovos em adultos sobreviventes foi praticamente nula. Se esse efeito não for considerado, podem-se efetuar pulverizações desnecessárias de inseticidas, o que
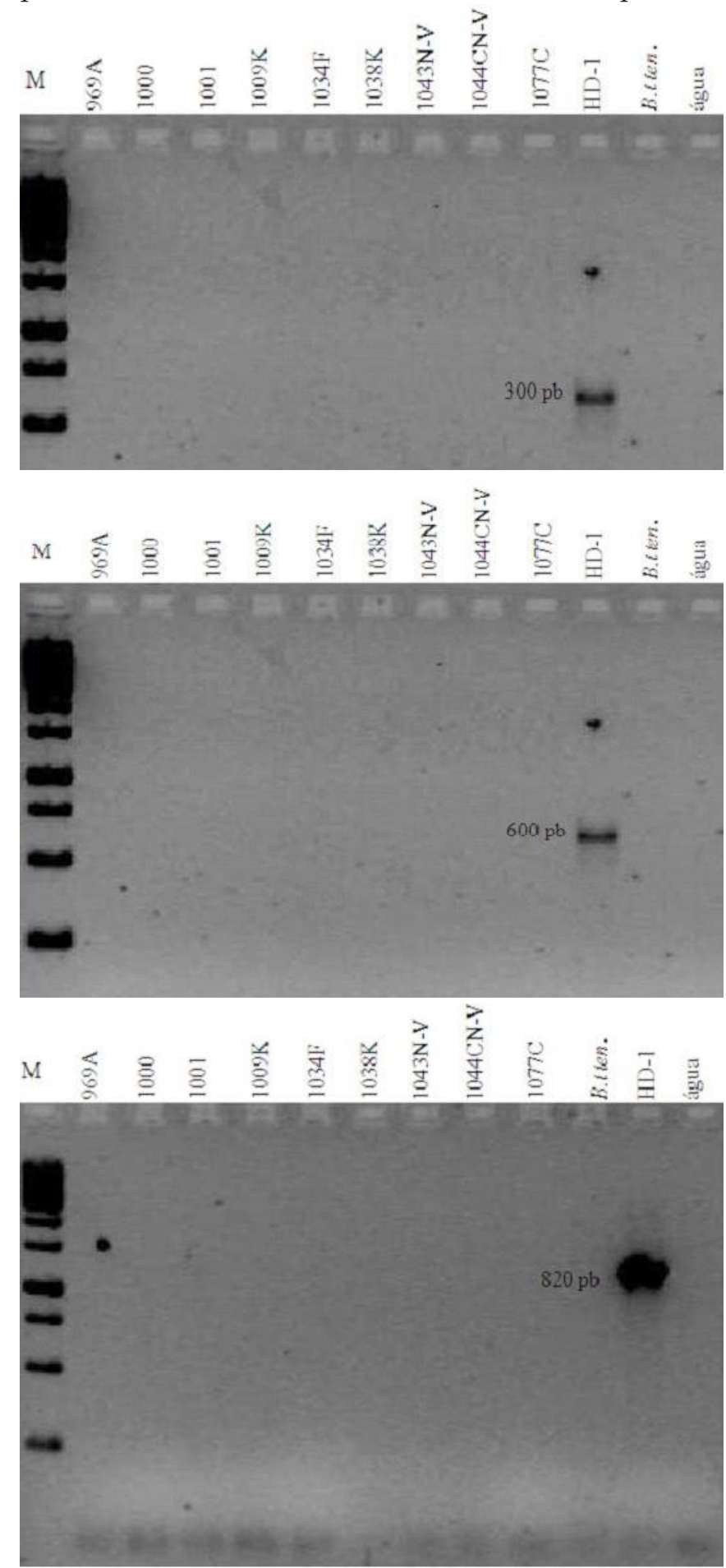

resulta em elevação do custo/produção, maior contaminação ambiental e prejuízos aos inimigos naturais presentes na área.

O Btk é muito usado no mundo para o controle de pragas, porém possui baixa persistência após a aplicação devido à degradação pela luz solar e chuva (BEHLE et al., 1997). As práticas atuais de controle microbianoignoram frequentementea possibilidade de evolução da resistência, contudo, o uso sustentado dos bioinseticidas depende de uma consideração desse fenômeno (JANMAAT, 2007).

Fig. 1-Eletroforograma de material genético dos isolados de Bacillus thuringiensis amplificados com a utilização dos iniciadores cry1. CP: controle positivo (Bacillus thuringiensis $\mathrm{HD}-1$ ), CN: controle negativo (água) e Bacillus thuringiensis tenebrionis (B.t ten.), M: marcador molecular (1 Kb plus).

Fig. 2-Eletroforograma de material genético dos isolados de Bacillus thuringiensis amplificados com a utilização dos iniciadores cry2. CP: controle positivo (Bacillus thuringiensis HD-1), CN: controle negativo (água) e Bacillus thuringiensis tenebrionis (B.t ten.), M: marcador molecular (1 Kb plus).

Fig. 3-Eletroforograma de material genético dos isolados de Bacillus thuringiensis amplificados com a utilização dos iniciadores Vip. CP: controle positivo (Bacillus thuringiensis HD-1), CN: controle negativo (água) e Bacillus thuringiensis tenebrionis (B.t ten.), M: marcador molecular (1 Kb plus). 
Como não foi possível a identificação das toxinas específicas para Lepidoptera nos isolados estudados, provavelmente novas toxinas podem estar causando a mortalidade de T. ni, visto que os genes cry1, cry2 e Vip não foram identificados (Figs. 1, 2 e 3). Outras caracterizações moleculares com genes diferentes deverão ser feitas para descobrir quais toxinas Cry podem estar causando a mortalidade de T. ni.

Os resultados demonstram que isolados de Bt são virulentos para $T$. ni, porém, devem ser realizados vários estudos em laboratório. Posteriormente, devem-se identificar geneticamente quais são as proteínas, purificá-las para apresentarem apenas as toxinas de interesse e, por fim, testar produtos formulados mais puros e estáveis às condições ambientais, principalmente no que diz respeito à persistência da bactéria.

\section{AGRADECIMENTOS}

À Coordenação de Aperfeiçoamento de Pessoal de NívelSuperior (CAPES), pela concessão da bolsa.

\section{REFERÊNCIAS}

ABBOTT, W.S. A method of computing the effectiveness of a insecticide. Journal of Economic Entomology, v.18, p.265-266, 1925.

ABDUL-SATTAR, A.A.; WATSON, T.F. Effects of Bacillus thuringiensis var. kurstaki on tabacco budworm (Lepidoptera: Noctuidae) adult and egg stage. Journal of Economic Entomology, v.75, n.4, p.596-598, 1982.

ALVES, S.B.; MORAES, S.A. Quantificação de inóculo de patógenos de insetos. In: ALVES, S.B. (Ed.). Controle microbiano de insetos. Piracicaba: FEALQ, 1998. p.765-777.

BEHLE, R.W.; MCGUIRE, M.R.; SHASHA, B.S. Effects of sunlight and simulated rain on residual activity of Bacillus thuringiensis formulations. Journal of economic entomology, v.90, p.1560-1566, 1997.

BRAVO, A.; SARABIA, S.; LOPEZ, L.; ONTIVEROS, H.; ABARCA, C.; ORTIZ, A.; LINA, L.; VILLALOBOS, F.J.; PEÑA, G.; NUÑEZ-VALDEZ, M.; SOBERÓN, M.; QUINTERO, R. Characterization of cry genes in a mexican Bacillus thuringiensis strain collection. Applied and Environmental Microbiology, v.64, p.4965-4972, 1998.

BURTON, R.L. Mass reaning the com earworn in the laboratory. U.S. Department of Agriculture Presentation Pap Ars, p.33-134, 1969.

CERÓN, J.; ORTIZ, A.; QUINTERO, R.; GUERECA, L.; BRAVO, A. Specific PCR primers directed to identify cryI and cryIII genes within a Bacillus thuringiensis strains collection. Applied and Environmental Microbiology, v.61, p.3826-3831, 1995.

DIAS, J.M.C.S. Produção e utilização de bioinseticidas bacterianos. Pesquisa Agropecuária Brasileira, v.27, p.5976,1992

GALLO, D.; NAKANO, O.; NETO, S.S.; CARVALHO, R. P. L.; DE BAPTISTA, G. C.; FILHO, E.B.; PARRA, J.R.P.; ZUCCHI, R.A.; ALVES, S.B.; VENDRAMIM, J. D.; MARCHINI, L.C.; LOPES, J.R.S.; OMOTO, C. Entomologia agrícola. Piracicaba, FEALQ, 2002. 920p.

GLARE, T.R.; O`CALLAGHAN, M. Bacillus thuringiensis: biology, ecology and safety. Hoboken: John Wiley, 2000. 368p.

GUILLON, M. Current world situation on acceptance and marketing of biological control agents (bcas). Disponível em: <http:/ / www.ibma.ch/pdf/20041028\%20Presentation $\%$ 20BCAs $\% 20$ Thailand $\% 20 \% 20 \& \% 20$ Indonesia $\% 20$ Cuba.pdf>. Acesso em: 21 out. 2008.

IGNOFFO, C.M.; COUCH, T.L.; GARCIA, C.; KROHA, M.J. Relative activity of Bacillus thuringiensis var. kurstaki and B. thurirngiensis var. israelensis against larvae of Aedes aegypti, Culex quinquefasciatus, Trichoplusia ni, Heliothis zea and Heliothis virescens. Journal of Economic Entomology, v.74, p.218-222, 1981.

JANMAAT, A.F.; MYERS, J. Rapid evolution and the cost of resistance to Bacillus thuringiensis in greenhouse populations of cabbage loopers, Trichoplusia ni. Proceedings of the Royal Society of London, v.270, 2263-2270, 2003.

JANMAAT, A.F. Development of Resistance to the Biopesticide Bacillus thuringiensis kurstaki. In: VINCENT, C.; GOETTEL, M.S.; LAZAROVITS, G. (Ed.). Biological control: a global perspective, case studies from around the world. Wallingford: CAB International, 2007. p.179184.

JOST, D.J.; PITRE, H.N. Soybean looper and cabbage looper (Lepidoptera: Noctuidae) populations in cotton and soybean cropping systems in Mississippi. Journal of Entomological Science, v.37, p.227-235, 2002.

LEORA SOFTWARE. POLO-PC: An user's guide to Probit or Logit analysis. Berkely: LeOra Software, 1987.

LIMA, A.S.G.; GUIDELLI, A.M.; ABREU, I.L.; LEMOS, M.V.F. Identification of new isolates of Bacillus thuringiensis using rep-PCR products and $\delta$-endotoxin electron microscopy. Genetics and Molecular Biology, v.25, p.225-229, 2002.

LIU, T.X.; SPARKS JUNIOR., A.N.; CHEN, W.; LIANG, G.M.; BRISTER, C. toxicity, persistence, and efficacy of indoxacarb on cabbage looper (Lepidoptera: Noctuidae) on cabbage. Journal of Economic Entomology, v.95, n.2, p.360-367, 2002. 
LOGUERCIO, L.L.; SANTOS, C.G.; BARRETO, M.R.; GUIMARAES, C.T.; PAIVA, E. Association of PCR and feeding bioassays as a large-scale method to screen tropical Bacillus thuringiensis isolates for a cry constitution with higher insecticidal effect against Spodoptera frugiperda (Lepidoptera: Noctuidae) larvae. Letters in Applied Microbiology, v.32, p.362-367, 2001.

MacINTOSH, S.C.; KISHORE, G.M.; PERLAK, F.J.; MARRONE, P.G.; STONE, T.B.; SIMS, S.R.; FUNCHS, R.L. Potentiation of Bacillus thuringiensis insecticidal activity by serine protease inhibitors. Journal of Agricultural and Food Chemistry, v.38, p.1145-1152, 1990.

MOSCARDI, F.; SOSA-GÓMEZ, D.R.; CORRÊIAFERREIRA, B.S. Soybean IPM in Brazil, with emphasis on biological control tactics. In: WORLD SOYBEAN RESEARCH CONFERENCE, 6., 1999, Chicago, USA. Proceedings. Chicago, 1999. v.6, p.331-339.

PARRA, J.R.P.; BOTELHO, P.S.M.; CORRÊA-FERREIRA, B.S.; BENTO, J.M.S. Controle biológico: terminologia. In: BENTO, J.M.S. (Ed.). Controle biológico no Brasil: parasitóides e predadores. São Paulo: Manole, 2002. p.1-16.

POLANCZYK, R.A.; ALVES, S. Bacillus thuringiensis: uma breve revisão. Agrociência, v.7, n.2, p.1-10, 2003.

POLANCZYK, R.A.; SILVA, R.F.P. da.; FIUZA, L.M. Isolamento de Bacillus thuringiensis BERLINER a partir de amostras de solos e sua patogenicidade para Spodoptera frugiperda (J. E. Smith) (Lepidoptera: Noctuidae). Agrociência, v.10, n.2, p.209-214, 2004.

PRATISSOLI, D.; POLANCZYK, R.A.; GRECCO, E.D.; FERREIRA, R.A.; HOLTZ, A. Efeito entomotóxico de novos isolados de Bacillus thuringiensis em duas populações de Spodoptera frugiperda oriundas de minas gerais e do espírito santo. Revista Brasileira de Milho e Sorgo, v.6, n.2, p.140-148, 2007.

SHELTON, A.M.; ANDALORO, J.T.; BARNARD, J. Effects of cabbage looper, imported cabbage worm, and diamondback moth on fresh market and processing cabbage. Journal of Economic Entomology, v.75, p.742-745, 1982.

SHOREY, H.H.; ANDRES, L.A.; HALE, R.L. The biology of Trichoplusia ni (Lepidoptera: Noctuidae). I. Life history and behavior. Annals of the Entomological Society of America, v.55, p.591-597, 1962.

SILVA-WERNECK, J.O.; ABREU NETO, J.R.M.V.; TOSTES, A.N.; FARIA, L.O.; DIAS, J.M.C.S. Novo isolado de Bacillus thuringiensis efetivo contra a lagartado-cartucho. Pesquisa Agropecuária Brasileira, v.35, n.1, p.221-227, 2000.

SWIECICKA, I.; BIDESHI, D.K.; FEDERICI, B.A. Novel Isolate of Bacillus thuringiensis subsp. thuringiensis that produces a quasicuboidal crystal of Cry1Ab21 toxic to larvae of Trichoplusia ni. Applied and Environmental Microbiology, v74, p.923-930, 2008.

VALADARES-INGLIS, M.C.; MELO, I.S. Métodos de extração de DNA e sua aplicação em estudos genéticos e ecológicos. In: MELO, I.S.; AZEVEDO, J.L. (Ed.).

Controle biológico. Embrapa-CNPMA, 1998. v.1, p.187-203.

Recebido em 16/7/09

Aceito em 29/10/10 